\title{
Sudan University of science and technology Graduate College
}

\author{
Mohamed Said Ahmed Alawad \\ *Corresponding Author: Mohamed Said Ahmed Alawad, Sudan

\begin{abstract}
Abbreviations constitute a significantly salient part of any scientific discipline and hence scientific language of our modern age. Only recently the world has witnessed an unprecedented expansion of learning and science and that a hell of countless and a whole system of naming or nomenclature is needed to produce the proper naming taxonomy. Hence, many words and terms have been utilized to express the newly emerging concepts. Many of them are compound phrases and high-frequency terms, and if we use them as they are, our speech and writing become very lengthy and boring. That is why people prefer the short forms (abbreviations)
\end{abstract} \\ for frequently used compound phrases.
}

Keywords: abbreviation, scientific names, nomenclature, expansion of learning.

\section{INTRODUCTION}

The foremost rationale behind the creation and use of abbreviations is to save time and reduce the volume of speech and writing to facilitate engineers' communication. The other intention is the explicitness, fluency, and beauty of our speech and writing. Any method, which can help us to achieve these goals, is acceptable. Abbreviations contribute to faster writing, reading, speaking, and better understanding of technical and scientific articles, reports, and lectures. They can save time and money by reducing the time and cost of writing, typing, editing, and composition resetting costs. They also reduce the space required for texts, tables, and diagrams. Therefore, they are very good tools to enhance any live and dynamic language.

The words of the English and other European languages comprise a few special characters implying distinct technical meanings, such as for wavelength or for phase. In these languages, abbreviations play a similar role, but each of them implies the meaning of a "phrase" instead of a "word." Thus, they can be considered as the elements of that language and are treated like the original words. Sometimes, the short form of a phrase is more common than that of its original form because they are very proper and effective tools for communication. In most languages, especially in English, coining abbreviations is a common practice and most of the high-frequency compound terms are used in short forms. For this reason, the abbreviations of a language are considered as "a language within that language", and from the socio-linguistic point of view, they are comparable with a "dialect." Therefore, utilization of abbreviations is inevitable and it is a wise decision to take action for their standardization.

\section{ACRONYM}

An acronym is a pronounceable word formed from the first letter or first few letters of each word in a phrase or title. Sometimes the newly-combined letters create a new word that takes the place in everyday language. Using this shortened form of a word or phrase can speed up communication. Here is a list of common acronyms, listed by category.

Some of these acronyms are very widely used, making them some of the most popular to appear in the English language.

- RADAR - Radio detecting and ranging

- LASER - Light amplification by the stimulated emission of radiation.

- NATO - The North Atlantic Treaty Organization.

- UNICEF - The United Nations International Children's Emergency Fund. 
- SCUBA - Self-contained underwater breathing apparatus.

- WASP - White Anglo Saxon Protestant.

According to Wikipedia there are no universal standards of the multiple names for such abbreviations and of their orthographic styling. In English and most other languages, such abbreviations historically had limited use, but they became much more common in the 20th century. Acronyms are a type of word formation process, and they are viewed as a subtype of blending.

Certainly an abbreviation is any type of shortened form, such as words with the middle omitted (for example, $R d$ for road or $D r$ for Doctor), an acronym is a word formed from the first letter or first few letters of each word in a phrase (such as sonar, created from sound navigation and ranging). Attestations for Akronym in German are known from 1921, and for acronym in English from 1940.

The distinction is not well-maintained. According to Merriam-Webster's Dictionary of English Usage: "A number of commentators ... believe that acronyms can be differentiated from other abbreviations in being pronounceable as words. Dictionaries, however, do not make this distinction because writers in general do not. ... Initialism, an older word than acronym, seems to be too little known to the general public to serve as the customary term standing in contrast with acronym in a narrow sense." About the use of acronym to only mean those pronounced as words, Fowler's Modern English Usage (3rd ed.) states: "The limitations of the term being not widely known to the general public, acronym is also often applied to abbreviations that are familiar but are not pronounceable as words. ... Such terms are also called initialisms."

There is no special term for abbreviations whose pronunciation involves the combination of letter names and words or word-like pronunciations of strings of letters, such as JPEG /'dzerpeg/ and $M S$ $D O S /, \varepsilon m \varepsilon s^{\prime} \mathrm{dps} /$. There is also some disagreement as to what to call abbreviations that some speakers pronounce as letters and others pronounce as a word. For example, the terms URL and IRA can be pronounced as individual letters: /,ju: a:r' $\varepsilon 1 /$ and /, al, a:r'el/, respectively; or as a single word: /'3:rl/ and /'aiərə/, respectively.

\section{ACronyms Viewed from a Historical Perspective}

Like metonymy, acronymy is a linguistic process that has existed throughout history but for which there was little to no naming, conscious attention, or systematic analysis until relatively recent times. Like metonymy, it became much more common in the 20th century than it had formerly been. Ancient examples of acronymy (regardless of whether there was metalanguage at the time to describe it) include the following:

(i) Acronyms were used in Rome before the Christian era. For example, the official name for the Roman Empire, and the Republic before it, was abbreviated as SPQR (Senatus Populusque Romanus). Inscriptions dating from antiquity, both on stone and on coins, use a lot of abbreviations and acronyms to save room and work. For example, Roman first names, of which there was only a small set, were almost always abbreviated. Common terms were abbreviated too, such as writing just "F" for filius, meaning "son of", a very common part of memorial inscriptions mentioning people. Grammatical markers were abbreviated or left out entirely if they could be inferred from the rest of the text.

\section{AbbreViations: Historical ReVieW}

Abbreviations have a long history, created so that spelling out a whole word could be avoided. This might be done to save time and space, and also to provide secrecy. Shortened words were used and initial letters were commonly used to represent words in specific applications. In classical Greece and Rome, the reduction of words to single letters was common. In Roman inscriptions, "Words were commonly abbreviated by using the initial letter or letters of words, and most inscriptions have at least one abbreviation." However, "some could have more than one meaning, depending on their context. (For example, A can be an abbreviation for many words, such as ager, amicus, annus, as, Aulus, Aurelius, aurum and avus.

Abbreviations in English were frequently used from its earliest days. Manuscripts of copies of the old English poem Beowulf used many abbreviations, for example 7 or \& for and, and $y$ for since, so that 
"not much space is wasted". The standardisation of English in the 15th through 17th centuries included such a growth in the use of abbreviations. At first, abbreviations were sometimes represented with various suspension signs, not only periods. For example, sequences like 〈er〉 were replaced with $\langle 0\rangle$, as in 〈masto〉 for master and 〈exacobate〉 for exacerbate. While this may seem trivial, it was symptomatic of an attempt by people manually reproducing academic texts to reduce the copy time. An example from the Oxford University Register, 1503:

\section{Masts subwardens y smède me to you. And whers y wrot to you the last wyke that $y$ trouyde itt good to differrs thelections ovs to quĩdenas tinitatis y have be thought me syns that itt woll be thens a bowte mydsoms.}

The Early Modern English period, between the 15th and 17th centuries, had abbreviations like $y^{e}$ for $P^{e}$, used for the word the: "hence, by later misunderstanding, Ye Olde Tea Shoppe."

During the growth of philological linguistic theory in academic Britain, abbreviating became very fashionable. The use of abbreviation for the names of J. R. R. Tolkien and his friend C. S. Lewis, and other members of the Oxford literary group known as the Inklings, are sometimes cited as symptomatic of this. Likewise, a century earlier in Boston, a fad of abbreviation started that swept the United States, with the globally popular term OK generally credited as a remnant of its influence.

After World War II, the British greatly reduced the use of the full stop and other punctuation points after abbreviations in at least semi-formal writing, while the Americans more readily kept such use until more recently, and still maintain it more than Britons. The classic example, considered by their American counterparts quite curious, was the maintenance of the internal comma in a British organization of secret agents called the "Special Operations, Executive"--S.O.,E"—which is not found in histories written after about 1960.

But before that, many Britons were more scrupulous at maintaining the French form. In French, the period only follows an abbreviation if the last letter in the abbreviation is not the last letter of its antecedent: "M." is the abbreviation for "monsieur" while "Mme" is that for "madame". Like many other cross-channel linguistic acquisitions, many Britons readily took this up and followed this rule themselves, while the Americans took a simpler rule and applied it rigorously.

Over the years, however, the lack of convention in some style guides has made it difficult to determine which two-word abbreviations should be abbreviated with periods and which should not. The U.S. media tend to use periods in two-word abbreviations like United States (U.S.), but not personal computer (PC) or television (TV). Many British publications have gradually done away with the use of periods in abbreviations.

Minimization of punctuation in typewritten material became economically desirable in the 1960s and 1970s for the many users of carbon-film ribbons since a period or comma consumed the same length of non-reusable expensive ribbon as did a capital letter.

Widespread use of electronic communication through mobile phones and the Internet during the 1990s allowed for a marked rise in colloquial abbreviation. This was due largely to increasing popularity of textual communication services such as instant- and text messaging. SMS, for instance, supports message lengths of 160 characters at most (using the GSM 03.38 character set). This brevity gave rise to an informal abbreviation scheme sometimes called Textese, with which $10 \%$ or more of the words in a typical SMS message are abbreviated. ${ }^{[9]}$ More recently Twitter, a popular social networking service, began driving abbreviation use with 140 character message limits.

\section{Modern EngLiSh STYLE}

In modern English, there are several conventions for abbreviations, and the choice may be confusing. The only rule universally accepted is that one should be consistent, and to make this easier, publishers express their preferences in a style guide. Questions which arise include those in the following subsections.

If the original word was capitalized then the first letter of its abbreviation should retain the capital, for example Lev. for Leviticus. When a word is abbreviated to more than a single letter and was originally 
spelled with lower case letters then there is no need for capitalization. However, when abbreviating a phrase where only the first letter of each word is taken, then all letters should be capitalized, as in YTD for year-to-date, PCB for printed circuit board and FYI for for your information. However, see the following section regarding abbreviations that have become common vocabulary: these are no longer written with capital letters.

\begin{tabular}{|l|l|l|l|}
\hline \multicolumn{1}{|c|}{ Example } & \multicolumn{1}{|c|}{ Category } & Short form & \multicolumn{1}{c|}{ Source } \\
\hline Doctor & Contraction & Dr & D__r \\
\hline Professor & Abbreviation & Prof. & Prof... \\
\hline The Reverend & Abbreviation & Rev. & Rev... \\
\hline The Reverend & Contraction & Revd & Rev—_d \\
\hline The Right Honourable & Contraction and Abbreviation & Rt Hon. & R_— t Hon... \\
\hline
\end{tabular}

In American English, the period is usually included regardless of whether or not it is a contraction, e.g. Dr. or Mrs.. In some cases, periods are optional, as in either US or U.S. for United States, EU or E.U. for European Union, and UN or U.N. for United Nations. There are some house styles, however-American ones included - that remove the periods from almost all abbreviations. For example:

- The U.S. Manual on Uniform Traffic Control Devices advises that periods should not be used with abbreviations on road signs, except for cardinal directions as part of a destination name. (For example, "Northwest Blvd", "W. Jefferson", and "PED XING" all follow this recommendation.)

- AMA style, used in many medical journals, uses no periods in abbreviations or acronyms, with almost no exceptions. Thus eg, ie, vs, et al., Dr, Mr, MRI, ICU, and hundreds of others contain no periods. The only exceptions are "No." (to avoid the appearance of "No"); initials within persons' names (such as "George R. Smith"); and "St." within persons' names when the person prefers it (such as "Emily R. St. Clair") (but not in city names such as St Louis or St $\mathrm{Paul}$ ). (AMA style also forgoes italic on terms long since naturalized into English from Latin, New Latin, other languages, or ISV; thus, no italic for eg, ie, vs, et al., in vivo, in vitro, or in situ.)

\section{CONCLUSiON}

Acronyms that were originally capitalized (with or without periods) but have since entered the vocabulary as generic words are no longer written with capital letters nor with any periods. Examples are sonar, radar, lidar, laser, snafu, and scuba.

Today, spaces are generally not used between single-letter abbreviations of words in the same phrase, so one almost never encounters "U. S."

When an abbreviation appears at the end of a sentence, only one period is used: The capital of the United States is Washington, D.C

\section{BIBLIOGRAPHY}

[1] New Hart's Rules: The handbook of style for writers and editors. Oxford University Press, 2005. ISBN 019-861041-6.

[2] The British Cyclopaedia of the Arts, Sciences, History, Geography, Literature, Natural History, and Biography, Wm. S. Orr and Company, 1838, p.5.

[3] Adkins, L., Handbook to Life in Ancient Rome, Infobase Publishing, 2004, p. 261.

[4] Gelderen, E. v, , A History of the English Language: Revised edition, John Benjamins Publishing Company, 2014, Ch. 41. 
[5] Spelling Society: Shortcuts 1483-1660 Archived October 15, 2007, at the Wayback Machine. Doesn't work.

[6] Lass, R., The Cambridge History of the English Language, Cambridge University Press, 2006, Vol. 2, p. 36.

[7] "The Choctaw Expression 'Okeh' and the Americanism 'Okay"'. Jim Fay. 2007-09-13. Archived from the original on 2010-12-24. Retrieved 2008-05-12.

[8] "What does "OK" stand for?". The Straight Dope. Archived from the original on 12 May 2008. Retrieved 2008-05-12.

[9] Crystal, David. Txtng: the Gr8 Db8. Oxford: Oxford University Press, 2008. ISBN 978-0-19-954490-5

[10] Allen, Robert, ed. (2008). "Full stop". Pocket Fowler's Modern English Usage (2nd ed.). Oxford University Press. ISBN 9780191727078.

Citation: Mohamed Said Ahmed Alawad. "Sudan University of science and technology Graduate College" International Journal of Humanities Social Sciences and Education (IJHSSE), vol 5, no. 1, 2018, pp. 11-15. doi: http://dx.doi.org/10.20431/2349-0381.0501003.

Copyright: () 2018 Authors. This is an open-access article distributed under the terms of the Creative Commons Attribution License, which permits unrestricted use, distribution, and reproduction in any medium, provided the original author and source are credited. 